\title{
A final reaction to Jackendoff
}

\author{
Pieter A. M. SEUREN \\ Max Planck Institute for Psycholinguistics
}

Ray Jackendoff and I seem to concur in most essential points. At the level of overall architecture, his parallel grammar model (Jackendoff 2002:199) and my model of SEMANTIC SYNTAX (SeSyn; Seuren 1996) bear a nontrivial resemblance. Apart from technical details such as the properties of the rule systems concerned, these models seem to differ mainly in two respects. First, for Jackendoff, perception simply follows the reverse procedure of production (Jackendoff 2002:197); they are the top-down and the bottomup sides of the same coin. Then, Jackendoff's model places phonology, syntax, and conceptual structure (semantics) in parallel, while in SeSyn, as in Levelt 1989:9, they are sequential in the order required for production (Seuren 1996, 2009:232-41). For Jackendoff, competence is symmetrical between speaking and comprehending. For me (as for Levelt), competence is asymmetrical: the production model forms the core of the system, while, for the most part, comprehension rides on the back of the production system.

Without pressing my case too much here, I may observe that most utterances by far are presented in a highly restricted situational context and under a topic-comment modulation, which implies that the topic has already been processed and only the comment needs interpretation. In this perspective, comprehension is largely a matter of anticipation and analysis-by-synthesis (or reconstruction-by-hypothesis), as is reported by many authors (see Seuren 2009:237-41). Such a system requires a well-organized feedback and selfmonitoring network, as is stressed by Levelt (1989:13) and myself (ibid.). On the production side, it is well known that lexical selection must precede syntactic structuring. What is in English There is no statutory limitation on murder is in German Mord verjährt nicht, simply because English has no verbal equivalent for the German verb verjähren (in the legal sense): syntactic structure follows the instructions of the lexical item chosen.

In any case, the question needs further research and further dialogue. I feel this discussion has been useful, as it highlights the crucial importance of clarity regarding the architecture of linguistic competence. In this context, (non)reversability of comprehension with regard to production and (non)parallelism of phonology, grammar, and semantics (conceptual structure) constitute cutting-edge problems.

\section{REFERENCES}

JACKENDOFF, RAY. 2002. Foundations of language: Brain, meaning, grammar, evolution. Oxford: Oxford University Press.

Levelt, Willem J. M. 1989. Speaking: From intention to articulation. Cambridge, MA: MIT Press.

Seuren, Pieter A. M. 1996. Semantic syntax. Oxford: Blackwell.

Seuren, Pieter A. M. 2009. Language in cognition (= Language from within, vol. 1). Oxford: Oxford University Press. 